\title{
Homologous recombination in DNA repair and DNA damage tolerance
}

\author{
Xuan $\mathrm{Li}^{1}$, Wolf-Dietrich Heyer ${ }^{1,2}$ \\ ${ }^{1}$ Section of Microbiology University of California, Davis, Davis CA 95616-8665, USA, ${ }^{2}$ Section of Molecular and Cellular Biology, \\ University of California, Davis, Davis CA 95616-8665, USA
}

Homologous recombination (HR) comprises a series of interrelated pathways that function in the repair of DNA double-stranded breaks (DSBs) and interstrand crosslinks (ICLs). In addition, recombination provides critical support for DNA replication in the recovery of stalled or broken replication forks, contributing to tolerance of DNA damage. A central core of proteins, most critically the RecA homolog Rad51, catalyzes the key reactions that typify HR: homology search and DNA strand invasion. The diverse functions of recombination are reflected in the need for context-specific factors that perform supplemental functions in conjunction with the core proteins. The inability to properly repair complex DNA damage and resolve DNA replication stress leads to genomic instability and contributes to cancer etiology. Mutations in the $B R C A 2$ recombination gene cause predisposition to breast and ovarian cancer as well as Fanconi anemia, a cancer predisposition syndrome characterized by a defect in the repair of DNA interstrand crosslinks. The cellular functions of recombination are also germane to DNA-based treatment modalities of cancer, which target replicating cells by the direct or indirect induction of DNA lesions that are substrates for recombination pathways. This review focuses on mechanistic aspects of HR relating to DSB and ICL repair as well as replication fork support.

Keywords: DNA repair, double-strand breaks, genome stability, homologous recombination, interstrand crosslinks, stalled replication forks

Cell Research (2008) 18:99-113. doi: 10.1038/cr.2008.1; published online 1 January 2008

\section{Introduction}

DNA damage is a fact of life as a consequence of endogenous sources and processes as well as exogenous sources [1]. Homologous recombination (HR) is a DNA metabolic process found in all forms of life that provides high-fidelity, template-dependent repair or tolerance of complex DNA damages including DNA gaps, DNA double-stranded breaks (DSBs), and DNA interstrand crosslinks (ICLs). In addition to its role in preserving the genome, HR plays a prominent role in faithfully duplicating the genome by providing critical support for DNA replication and telomere maintenance. The competition between the HR and nonhomologous end-joining (NHEJ) pathways in the repair of DSBs is specifically addressed in the chapter by Shrivastav et al. (in this issue). HR competes in DNA damage toler-

Correspondence: Wolf-Dietrich Heyer

Tel: +1-530-752-3001; Fax: +1-530-752-3011

E-mail: wdheyer@ucdavis.edu ance with translesion synthesis (TLS) pathways, and TLS polymerases are discussed in dedicated chapters by Gan et al. and Andersen et al. (in this issue). In ICL repair, HR is envisioned to collaborate with nucleotide excision repair (NER), and NER is the topic of the chapter by Shuck et al. (in this issue).

Many aspects of HR have been reviewed previously, and the reader is referred to these outstanding contributions [2-9]. This review focuses on the mechanism of HR during DSB (Figure 1) and ICL repair (Figure 3), as well as in the recovery of stalled and broken replication forks (Figure 2), based on studies with proteins from the budding yeast Saccharomyces cerevisiae and humans (Table 1). The significance of the role of HR in maintaining genome stability and tumor suppression is highlighted by the tumor suppressor protein BRCA2 $[6,10,11]$. BRCA2 establishes a role of HR in cancer suppression, and also provides the nexus between HR and Fanconi anemia (FA), a classical DNA repair cancer predisposition syndrome that defines a molecular pathway with a function in ICL repair $[12,13]$. 


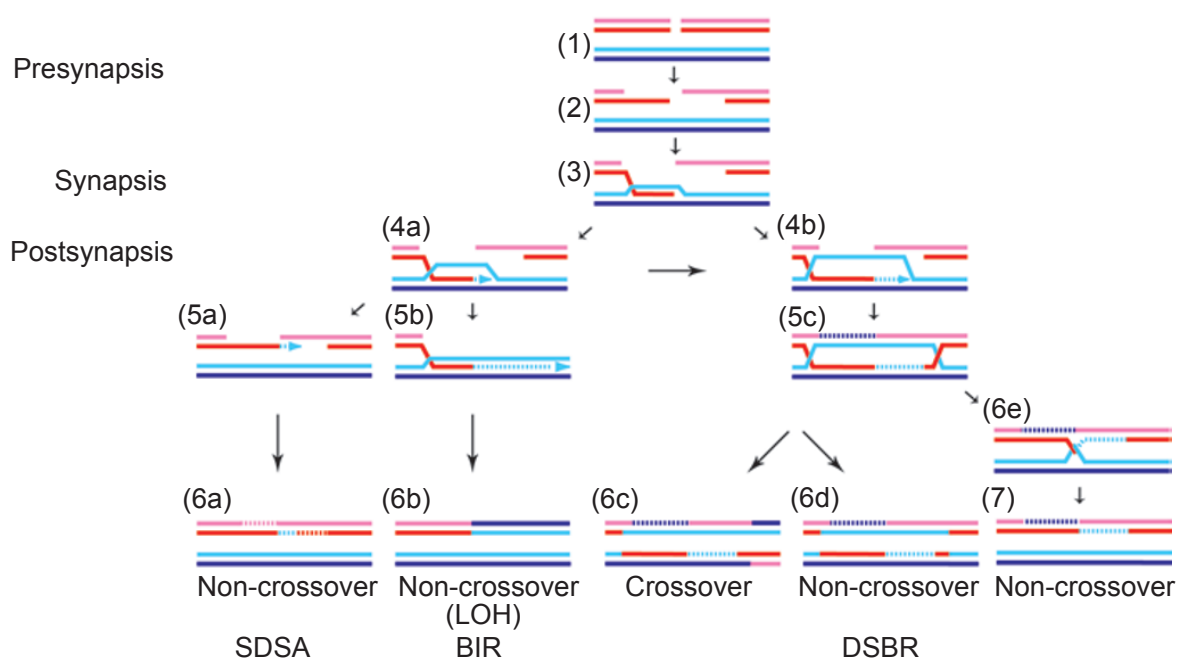

Figure 1 Pathways of recombination in DSB repair. Homologous recombination can be conceptually divided into three stages: presynapsis, synapsis, and postsynapsis. During presynapsis, DSB ends are recognized and processed to a 3'-OH ending single-stranded tail (steps 1-2). In synapsis, DNA strand invasion by the Rad51-ssDNA filament generates a D-loop (step 3). At least three different pathways are proposed after the D-loop intermediate. In synthesis-dependent strand annealing (SDSA, steps $4 a-5 a-6 a)$, the invading strand is disengaged after DNA synthesis and annealed with the second end, leading to localized conversion without crossover. This process may involve multiple rounds of invasion, synthesis, and disengagement. In break-induced replication (BIR, steps $4 a-5 b-6 b)$, the D-loop is assembled into a full replication fork, copying the entire distal part of the chromosome to result in loss-of heterozygosity (LOH). In double-strand break repair (DSBR, steps 4b - 5c - 6c-e - 7), both ends of the DSB are engaged, either by independent strand invasion or by second end capture, leading to double Holliday junction formation. The junction can be processed by either a resolvase into non-crossover or crossover products (steps $6 \mathrm{c}$ and $\mathrm{d}$ ) or dissolved by a mechanism involving BLM-mediated branch migration and TOPOIIl $\alpha$-catalyzed dissolution of a hemicatenane (step 6e), leading exclusively to non-crossover products (step 7).

\section{Homologous recombination: the core mechanism of Rad51 filament formation and DNA strand inva- sion}

The central reaction of HR is homology search and DNA strand invasion by the Rad51-ssDNA presynaptic filament, positioning the invading $3^{\prime}$-end on a template duplex DNA to initiate repair synthesis (Figure 1). In the nuclear environment ssDNA is initially bound by the eukaryotic ssDNAbinding protein RPA, which displays higher affinity and specificity for ssDNA than $\operatorname{Rad} 51$ [5, 14]. Hence in vivo, Rad51 must assemble to form the presynaptic filament on RPA-coated ssDNA. What are the proteins and mechanisms required for targeting Rad51 to ssDNA and allow filament formation on RPA-coated ssDNA? How is assembly of the presynaptic filament controlled, and what triggers disassembly after DNA strand invasion? Key to the answers to these questions are the biochemical properties of the DNA binding and ATPase activities of the Rad51 protein. Also of importance are cofactors that promote assembly or stabilization of the Rad51 ssDNA-filament as well as the disassembly of the Rad51-DNA complexes (Table 1).

Rad51 is the eukaryotic RecA homolog that catalyzes homology search and DNA strand exchange [15]. Similar to $\operatorname{RecA}, \operatorname{Rad} 51$ binds cooperatively to ssDNA in a ternary complex with ATP at a stoichiometry of 1 protomer per 3-4 nucleotides, forming a right-handed filament with a helical pitch of $130 \AA[16,17]$. Despite the overall similarity between RecA and Rad51, important differences exist [18]. Unlike RecA, which shows a kinetic delay in binding dsDNA relative to ssDNA, Rad51 exhibits only little preference of binding to ssDNA over dsDNA $[18,19]$. Moreover, Rad51 protein exhibits an approximately 100 -fold lower ATPase activity than RecA on ssDNA or dsDNA $[15,18]$. How is Rad51 targeted to form filaments on ssDNA? What are the consequences of its reduced ATPase activity? The functions of Rad51 cofactors are important to rationalize these differences to RecA.

RPA is the heterotrimeric ssDNA-binding protein in eukaryotes and is involved in all DNA metabolic processes involving ssDNA [14]. The function of RPA in HR is complex. In vitro, RPA inhibits nucleation of the Rad51 filament on ssDNA, but stimulates recombination by eliminating secondary structure in ssDNA and by binding to the displaced strand of the D-loop [20,21]. The inhibitory effect of RPA on Rad51 filament formation is overcome 
A Leading-strand blockage

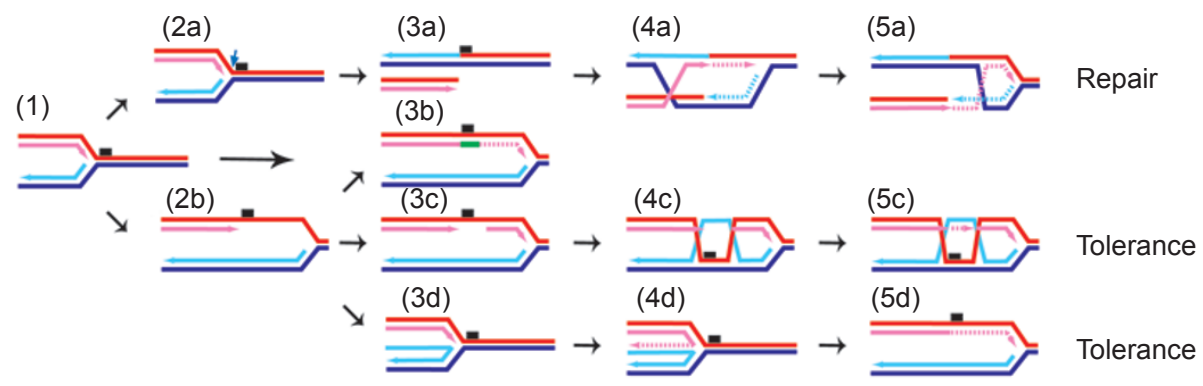

B Lagging-strand blockage

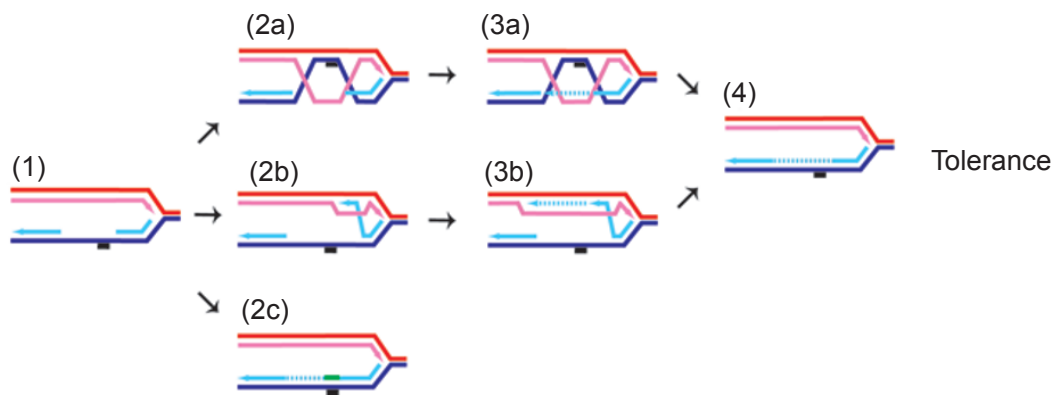

Figure 2 Pathways of homologous recombination at stalled/broken replication forks. (A) Possible pathways resolving leadingstrand blockage. Stalled replication forks (step 1) can be cleaved by an endonuclease to generate a one-sided DSB. One-sided DSB repair by recombination (steps $2 a-3 a-4 a-5 a)$ proceeds in analogy to BIR (Figure 1) involving DNA strand invasion and re-establishment of a functional fork. A single Holliday junction is created in the process. The initial blocking lesion must be either repaired or bypassed by TLS polymerases. TLS can also lead to direct bypass of the original blocking lesion (step $3 b$, green line). Uncoupling of lagging-strand synthesis (step $2 b$ ) can lead to direct lesion bypass by TLS (step $3 b$ ) or downstream re-initiation of leading strand synthesis, resulting in a leading strand gap, which can be repaired by recombination (steps $3 \mathrm{c}-4 \mathrm{c}$ - 5c). The different strand invasion pathways are not detailed here, but are shown below for lagging strand gaps (see b; steps $2 a-3 a-4$ and $2 b-3 b-4)$. The lesion may be repaired later or is tolerated. Alternatively, the fork could regress into a Holliday junction (also called a chicken foot), where the nascent lagging strand serves as a template for the leading strand (steps $3 \mathrm{~d}$ - 4d). Reversal of the chicken foot enables fork progression, and the blocking lesion may be repaired later or is tolerated (step 5d). (B) Possible pathways resolving lagging strand blockage. Downstream re-initiation of lagging-strand synthesis after blockage leaves a gap on the lagging strand (step 1), which can be repaired by recombination (steps $2 a-3 a / b-4)$. Initiation from the uninterrupted strand of the gap (step 2a) leads to formation of a paranemic joint that involves partial Holliday junctions and possible double Holliday junctions. Initiation by the $3^{\prime}$ end strand of the interrupted strand generates a D-loop ( $\left.2 b-3 b\right)$. The blockage can also be directly bypassed by TLS (step 2c; green line).

by Rad51 cofactors, collectively called mediator proteins, because they mediate nucleoprotein filament formation on RPA-coated ssDNA [22]. In vivo, mediators are required to form Rad51 filaments, a process that is monitored by the appearance of cytologically observable Rad51 foci or by chromatin immunoprecipitation. Using these biochemical, molecular and cytological criteria, the Rad55-Rad57 complex and Rad52 have been identified as the key mediators of Rad51 filament formation in budding yeast [23-25].

Rad55 and Rad57 are two Rad51 paralogs in S. cerevisiae that form a heterodimer with mediator activity, as they enable Rad51-mediated in vitro recombination in the presence of RPA-coated ssDNA [26]. There are five human Rad51 paralogs $(\operatorname{Rad} 51 B, \operatorname{Rad} 51 C, \operatorname{Rad} 51 D$,
Xrcc2, Xrcc3; see Table 1), but the overall low sequence conservation makes it difficult to assign which of the human $\operatorname{Rad} 51$ paralogs correspond to $\operatorname{Rad} 55-\operatorname{Rad} 57$ [5, 27]. Rad51C associates with Xrcc 3 and is also found in a complex with Rad51B, Rad51D, and Xrcc2 [28, 29]. A stable subcomplex of Rad51B-Rad51C was also shown to exhibit mediator function, allowing hRad51-mediated DNA exchange with hRPA-coated ssDNA in vitro [30]. The mechanism(s) by which the Rad51 paralogs function as mediators are unknown, but all are required in vivo for Rad51 filament formation. Genetic analysis suggests that the Rad51C-Rad51B-Rad51D-Xrcc2 and Xrcc3-Rad51C complexes have non-overlapping functions [31].

Rad52 forms a multimeric ring structure that binds 

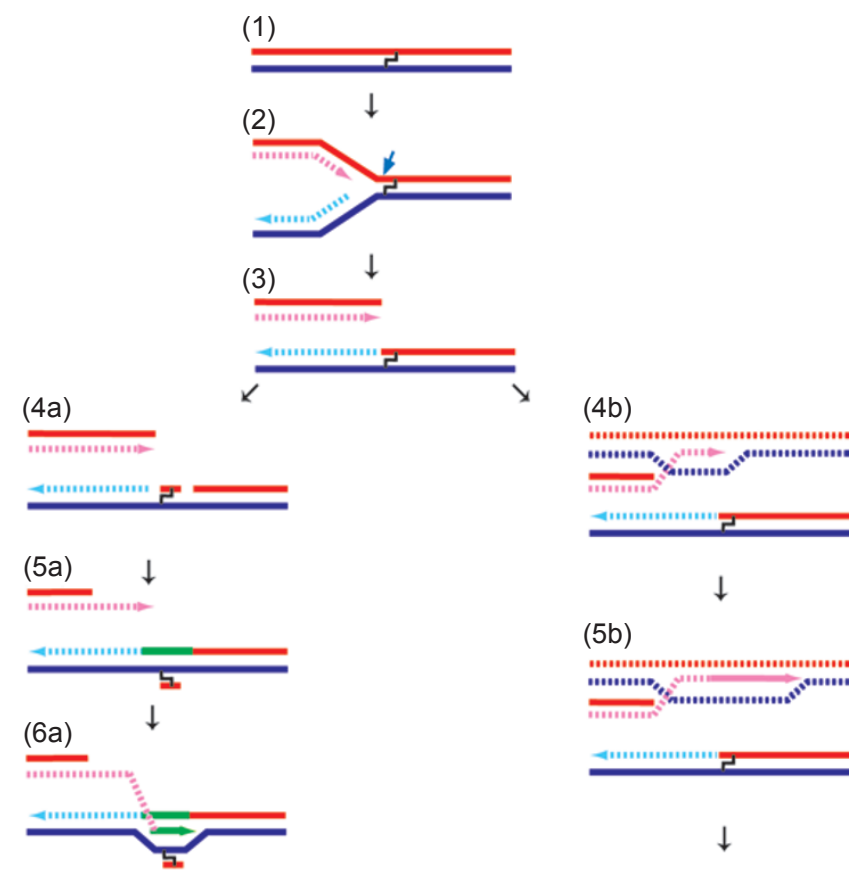

$\downarrow$

(5b)

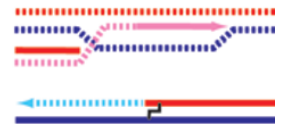

$\downarrow$

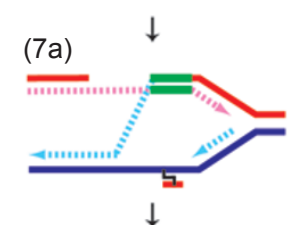

(6b)

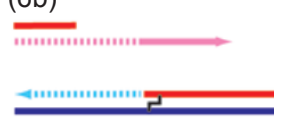

(8)

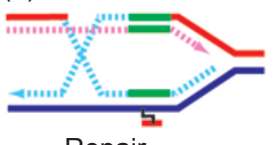

Repair

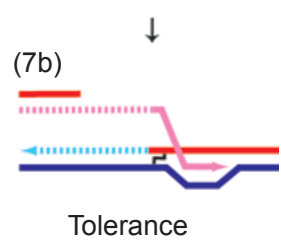

Figure 3 Homologous recombination and repair of DNA interstrand crosslinks. Possible pathways to resolve replication forks stalled at interstrand crosslinks. The stalled replication fork is recognized and cleaved by a specific endonuclease (hMus81-Eme1 [144]) in the leading-strand template to generate a one-sided DSB (steps 1-3). Introduction of a second incision on the other side of the ICL (step 4a) allows the lesion to flip out and to be bypassed by TLS (green line). The DSB is processed to form a 3'-OH ending single-stranded tail (step 5a) and to initiate DNA strand invasion (step 6a). The replication fork is restored (steps 7a) and the lesion is bypassed by TLS (green line). The lesion is eventually repaired, either after $\mathrm{HR}$ as drawn in step 8 or before (e.g. at step 5a). The DSB can also initiate DNA strand invasion using the homolog as a template (step 4b). DNA is synthesized across the lesion region (step $5 b$ ), disengaged (step $6 b$ ) and reinvasion of the sister chromatid behind the lesion site can lead to restoration of the replication fork and tolerance of the lesion $(7 \mathrm{~b}$; the step from $D$-loop to recovered fork are not drawn and equivalent to Figure 2A, steps 3a-4a-5a). The hypothetical steps for ICL repair by nucleotide excision repair are not drawn here. For additional schemes for ICL repair/tolerance at stalled replication forks or in non-replicating DNA see refs. [138, 139, 145]. preferentially to ssDNA on the outside of the ring through an N-terminal DNA binding domain $[32,33]$. Yeast Rad52 interacts with Rad51 as well as with RPA [34, 35], accelerates displacement of RPA from ssDNA by Rad51 [36], and allows efficient Rad51-mediated recombination involving RPA-coated ssDNA [37-39]. This mediator function of Rad52 does not account for the extreme HR defect of Rad52-deficient cells in yeast. This is because Rad52 also exhibits the unique ability to anneal homologous ssDNA coated by RPA [40]. Such an activity is thought to be critical in second-end capture [41], SDSA (synthesis-dependent strand annealing) and SSA (single-strand annealing) (see below). Unlike the yeast mutant, mouse rad52 mutants display an exceedingly mild recombination defect and no ionizing radiation (IR) sensitivity [42]. The reasons for this are not understood, but genetic experiments in chicken DT40 cells suggest a partially overlapping function between $\mathrm{Xrcc} 3$ and $\operatorname{Rad} 52$ [43]. It is not known which mammalian proteins have taken over functions exerted by the yeast Rad52 protein, but one candidate is BRCA2, which is not found in budding yeast.

The tumor suppressor BRCA2 is of special interest among the mediator proteins. Heterozygous mutations in $B R C A 2$ predispose to breast, ovarian as well as other tumor types. Moreover, bi-allelic loss of $B R C A 2$ function causes FA (see below) [6, 10-12]. BRCA2 is required for IR-induced Rad51 focus formation in vivo [44]. Experiments with the full-length Ustilago maydis homolog, BRH2, and fragments of the human protein demonstrated that BRCA2 targets Rad51 filament formation to the ssDNA-dsDNA junction on RPA-coated ssDNA [45-47]. The mechanism is likely to be complex, considering the size of BRCA2 (3 418 amino acids), the multitude of Rad51-binding sites (8 BRC repeats and a C-terminal site), and the importance of its interaction partners (see below). The structure of the BRC4 repeat revealed a molecular mimicry of the Rad51 subunit-subunit interface, suggesting that BRCA2, through its BRC motif, might serve as a nucleation point of the Rad51 filament [48]. The C-terminal Rad51-binding site preferentially binds to the filament form of Rad51 $[49,50]$. These results suggest that BRCA2 employs two mechanisms to favor Rad51 filament formation, nucleation and filament stabilization. The binding of the C-terminal site to Rad51 is negatively regulated by CDK phosphorylation on S3291, suggesting that BRCA2 function in HR is regulated throughout the cell cycle [51]. Besides its critical interaction with hRad51, BRCA2 was also found to physically interact with a number of other proteins $[6$, 10-12]. While the mechanistic function of these BRCA2interacting proteins remains to be determined, genetic experiments have shown that depletion of DSS1 $[52,53]$, PALB2 [54] (FANCN, see below), and BCCIP [55] affects 
Table 1 Homologous recombination proteins in S. cerevisiae and humans

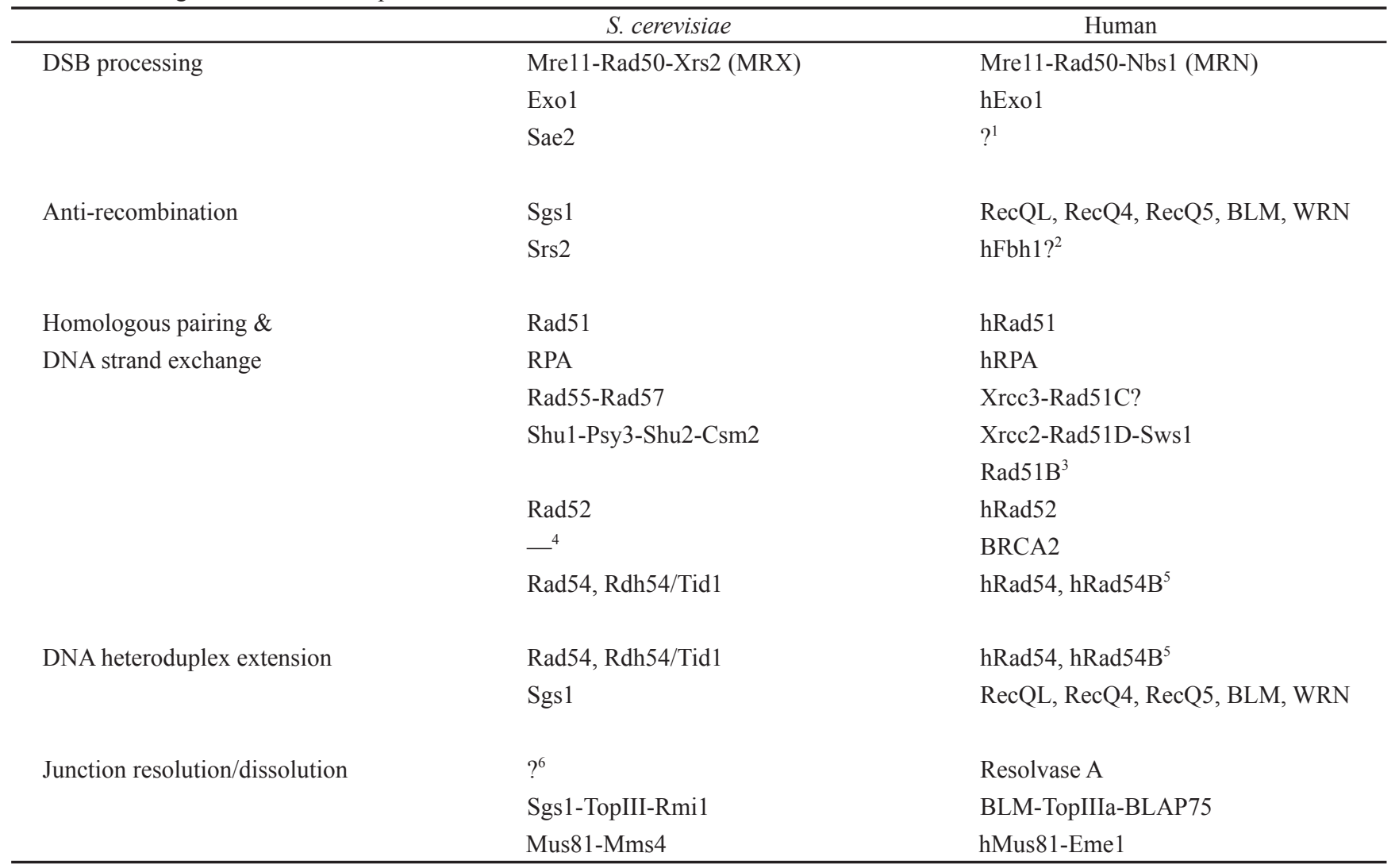

${ }^{1}$ No homolog has been identified yet in mammals.

${ }^{2}$ Based on phenotypes of the fission yeast Schizosaccharomyces pombe fbhl gene, it has been suggested that Fbh1 could function similarly to Srs 2 as an anti-recombinase [159].

${ }^{3}$ At present, there is no obvious Rad51B homolog in budding yeast, although it should be noted that the homology between the Rad51 paralogs is quite low, so that assignment of homologs may be somewhat uncertain.

${ }^{4}$ No BRCA2 homolog has been identified in S. cerevisiae, although the smut fungus Ustilago maydis has a sequence and functional homolog, BRH2 (see ref. [45]).

${ }^{5}$ hRad54 is evidently a homolog of S. cerevisiae Rad54. It remains unsettled whether hRad54B is a homolog of Rdh54/Tid1 [60].

${ }^{6}$ No activity equivalent to Resolvase A has been identified in S. cerevisiae, and the identity (gene/protein) of the Resolvase A activity is unknown.

HR. BRCA2 appears to be a regulatory integration point of the HR pathway.

Rad54 is a core factor of HR in budding yeast, and cells deficient for this protein reveal DNA damage sensitivities that are identical to those of a rad51 mutant $[4,56,57]$. In mice, Rad51 is essential, whereas Rad54-deficient cells or mice are viable $[58,59]$. It is unclear whether this reflects functional differences between the yeast and vertebrate Rad51 proteins (discussion in ref. [3]), undiscovered redundancies with the vertebrate Rad54 protein [60], or other reasons. Rad54 is a bidirectional motor protein that translocates at $\sim 300 \mathrm{bp} / \mathrm{s}$ on dsDNA powered by the hydrolysis of ATP [61]. Rad54 associates with and stabilizes the Rad51 presynaptic filament [62, 63], which targets Rad54 to the pairing site $[64,65]$. Rad54 stimulates DNA strand invasion by Rad51 in vitro by a mechanism that is poorly understood but requires its ATPase activity [56, 57, 66]. Rad54 also functions after synapsis. The protein dissociates Rad51 from the heteroduplex DNA, effectively acting as a turnover factor that allows access of DNA polymerases to the invading $3^{\prime}$ end $[67,68]$. The similarity to Snf2like chromatin remodeling factors and the ability to slide nucleosomes suggest that Rad54 might also be involved in chromatin remodeling during HR [69-71]. In addition, it was shown that the Rad54 motor can migrate branched DNA structures, including Holliday junctions [72, 73]. In vivo Rad54 is not required for Rad51 focus formation, but Rad51 foci display an extended half-life in Rad54-deficient cells, suggesting that Rad54 exerts critical functions after Rad51 filament assembly [60, 74, 75]. The biochemical analysis of Rad54 has revealed an astounding versatility, but its exact in vivo function(s) remains to be determined 
(reviews in refs. [56, 57]).

The core reaction of homology search and DNA strand invasion is central to all HR reactions. However, the different functional contexts of HR in DSB repair, replication fork support and ICL repair necessitate context-specific factors in the processing of the lesion, assembly of the Rad51 filament or in the processing of the primary DNA strand invasion intermediate, the D-loop. These factors and their functions will be discussed in the following sections within their specific functional contexts.

\section{Homologous recombination and repair of DSBs}

DSBs can be frank (two-sided) and one-sided; both are a major threat to genomic stability. Failure to repair DSBs or their misrepair can result in chromosome loss, chromosomal rearrangements, apoptosis, or carcinogenesis [76]. Endogenous sources or processes including mechanical stress (e.g. 'breakage-fusion-bridge cycles' [77]), transposition [78], immunoglobulin diversification [79], and meiosis [2] involve the accidental or programmed generation of two-sided DSBs. One-sided DSBs are primarily related to DNA replication and will be discussed in the next section. Of particular interest is the induction of DSBs by exogenous sources in the context of cancer therapy. IR exhibits potent anti-tumor activity. Random energy deposition by IR leads to a wide array of DNA damages, including DSBs, single-strand breaks, and a host of different base damages (e.g. thymine glycol) [80]. Among these, DSBs are the most genotoxic and are induced by clustered ionization from a single track of radiation leading to closely spaced single-stranded breaks at a single multiply damaged site [80]. IR-induced ssDNA breaks and base damages may interfere with DNA replication, potentially leading to onesided DSBs (see below). IR-induced DSBs often contain modified bases at their $3^{\prime}$ - and $5^{\prime}$-ends. Such ends with non-standard chemistry necessitate processing steps that are not needed when DSBs are introduced by nucleases in experimental model systems [4]. Intermediary metabolic products of Streptomycetes, including bleomycin, neocarcinostatin, and related compounds, have been effectively used in anti-tumor therapy [81]. They directly induce DSBs by attacking specific carbons in deoxyribose, leaving non-standard end-groups. A third class of DNA-based anti-tumor therapeutics is represented by topoisomerase inhibitors [82]. Topoisomerases are enzymes that open and close strands of DNA: type I topoisomerases open/close one strand, whereas type II topoisomerases open/close both strands at a time [83]. Both types involve a covalent DNAprotein bond in their catalytic cycle. This transition state can be stabilized by topoisomerase inhibitors leading to DSBs for type II inhibitors (e.g. etoposides) or single-stranded breaks for type I inhibitors (e.g. camptothecin) [82], which may become one-sided DSBs by replication run-off (Figure 2A; see ref. 84 for an alternative model). These damages pose a particular challenge for end-processing, as the topoisomerases are covalently attached to the 5'- ends (bacterial type I, bacterial and eukaryotic type II) or 3'-ends (eukaryotic type I) of the broken DNA. The existence of a specific enzyme, TDP1 (tyrosyl-DNA-phosphodiesterase), that cleaves the phosphodiester bond linking the active site tyrosine of eukaryotic type I topoisomerases to DNA shows that these complexes occur in normal cellular growth [85, 86]. In sum, the exact chemical nature of the DSB depends on the mechanism of its induction and will have an impact on its requirements for repair.

Several pathways compete for the repair of DSBs: HR, NHEJ, and SSA (see chapter by Shrivastav et al. in this issue and refs. $[4,87])$. HR comprises a series of related sub-pathways that use DNA strand invasion and templatedirected DNA repair synthesis, culminating in high-fidelity repair (Figure 1). Besides the classical DSBR (doublestrand break repair) route [88], genetic and molecular studies have proposed two further variations of the HR theme in the SDSA [89] and BIR [90, 91] (break-induced replication) sub-pathways. Here, we will discuss the mechanisms and proteins that are specifically required in DSB repair mediated by HR in addition to the core proteins described above.

All sub-pathways of HR share the same initial steps in processing the DSB to a $3^{\prime}$ overhanging tail, to which the assembly of the Rad51 filament is directed. This phase of HR is termed pre-synapsis (Figure 1). Nucleolytic processing of the DSBs involving non-standard chemistry, e.g. DSBs induced by IR, appears to specifically require the Mre11-Rad50-Xrs2 (MRX) complex (Table 1). Defects in this complex lead to significant IR sensitivity, but the repair of a 'clean' DSB induced by the HO-endonuclease proceeds with no or little reduction in viability, involving only a minimal delay in repair kinetics $[9,92,93]$. The $5^{\prime}-3^{\prime}$ exonuclease Exo1 [94] and the product of the SAE2 gene [95] are also involved in 5'-end resection, probably acting in concert with the MRX complex.

The homology search and DNA strand invasion are collectively called synapsis and catalyzed by the core proteins discussed in the previous section. These generate the Dloop intermediate, where the 3 '-end of the invading strand primes DNA synthesis off the template duplex DNA(Figure 1). The DSBR branch proceeds by engaging the second end of the DSB, by either second end capture through DNA annealing or a second invasion event. Annealing of the second end is catalyzed by the $\operatorname{Rad} 52$ protein, which exerts a unique function of being able to anneal complementary ssDNA bound to RPA [40, 41]. The resultant 
double Holliday junction ( $\mathrm{dHJ}$ ) is a substrate either for dissolution into non-crossover products by BLM-TOPOIII $\alpha$ or for resolution by a structure-specific endonuclease into crossover/non-crossover products (Figure 1, right). An endonuclease activity that exerts similar specificity for Holliday junctions as the bacterial RuvC protein has been identified in mammalian cell extracts [96]. The Resolvase A activity cleaves Holliday junctions into crossover and non-crossover products, but the identity of this activity has not yet been determined. Alternative processing of dHJs is afforded by the combined action of the BLM DNA helicase with the type I topoisomerase TOPOIII $\alpha$ and their cofactor BLAP75/Rmi1 [97-99]. In a process termed dissolution, BLM migrates the two junctions towards each other [98], and TOPOIII $\alpha$ removes the hemi-catenanes that topologically link the two duplexes. Importantly, this mechanism leads to an obligatory non-crossover outcome, providing a satisfying explanation for the increase in sister chromatid exchange in cells derived from Bloom's syndrome patients who are deficient for the BLM helicase. The corresponding budding yeast complex, Sgs1-Top3-Rmi1, has yet to be analyzed biochemically using dHJ substrates. Surprisingly, crossover suppression by Sgs 1 does not require its helicase activity during DSB repair [100], suggesting that Sgs1 may utilize other mechanisms than $\mathrm{dHJ}$ dissolution for crossover suppression, a notion that was also developed from analysis of crossover suppression by Sgs1 during meiotic recombination in $S$. cerevisiae [101].

In SDSA, the D-loop is dissolved after some DNA synthesis and the disengaged invading strand reanneals with the second end of the DSB, always forming non-crossover products (Figure 1, left). Reannealing to the second DSB end is believed to proceed similarly to second-end capture in DSBR, involving the yeast Rad52 protein (see above). It has been speculated that the BRCA2 protein may have a similar function [102]. Dissolution of D-loops almost certainly requires a motor protein, and genetic experiments in yeast have implicated the Srs2 helicase [103]. However, biochemical experiments using purified Srs2 protein failed to detect dissolution of Rad51-mediated D-loops [104], suggesting that a cofactor might be missing or that other proteins catalyze this step. Genetic experiments in Drosophila implicated the BLM helicase in D-loop dissolution [105], and biochemical data support this possibility, as purified BLM helicase specifically dissociates D-loops [106]. The aspect of crossover avoidance is one of the key features of SDSA that made this model attractive for DSB repair in somatic cells. Recombination in somatic cells is rarely associated with crossovers, and crossovers have the potential to generate genomic rearrangements and large-scale loss of heterozygosity (LOH) [107-109]. However, the dissolution of dHJs by BLM-TOPOIII $\alpha$ into non-crossover products $[97,98]$ (see above) reaffirms the possibility that dHJs may be an intermediate in DSB repair in somatic cells.

In BIR, the invading strand is postulated to establish a replication fork to copy the entire distal arm of the template chromosome, resulting in LOH (Figure 1, middle) $[90,110]$. Hence, the second end is never engaged and the genetic information of that fragment is lost. The contribution of BIR to the repair of interstitial DSBs in wild-type cells is uncertain, but in rad51 or mre 11 mutants, BIR makes a significant contribution to DSB repair [90, 93, 111]. However, BIR appears to be at least one mechanism responsible for alternative lengthening of telomeres, and both pathways share common genetic requirements $[110$, 112]. BIR may employ mechanisms similar to the repair of a broken replication fork (Figure 2A, step 3a), involving resection, Rad51 filament formation, and D-loop formation. Therefore, the mechanistic implications are discussed in the following section. The context of a one-sided DSB (S-phase, presence of replication fork components versus an event in G1 or G2) has likely a consequence on repair; e.g., it has been shown that efficient DSB resection is suppressed in budding yeast G1 cells [113].

In conclusion, DSB repair by HR is a group of interrelated conduits that share common core factors in the processing of DSBs, as well as in the assembly and function of the critical Rad51 filament, but that also likely have specific factors that mechanistically differentiate DSBR, SDSA, and BIR.

\section{Homologous recombination and replication fork support}

DNA lesions that interfere with the progress of the replicative DNA helicase or DNA polymerases lead to replication fork blockage or demise, producing DNA gaps or one-sided DSBs (Figure 2). Uncoupling of the replicative DNA helicase from the polymerases occurs when a lesion blocks the polymerase but not the helicase. This will generate excessive ssDNA, which could be the target of endonucleoytic processing, resulting in a one-sided DSB. A similar accumulation of unscheduled ssDNA occurs when the coordination of the leading and lagging strand synthesis is lost. In addition, single-stranded breaks induced by endogenous and exogenous sources, including reactive oxygen species [1], IR [80], covalent DNA-type I topoisomerases (see above), or other cellular processes (NER, BER; see chapters by Shuck et al., Hegde et al., and Horton et al. in this issue), may lead to the formation of one-sided DSBs due to runoff of the replication fork. Moreover, genetic experiments have identified natural DNA sequences that are difficult to replicate and lead to 
fork stalling and fork breakage. These processes have significant ramifications for human disease, as they involve fragile sites, which represent a common form of genomic instability in humans [114]. Specific protein factors like the Rrm3 DNA helicase support replication to successfully pass such obstacles [115]. Aberrant resolution of replication stress is a major cause of genomic instability, and provides a constant impetus for genetic change in highly replicative cancer cells [116].

Multiple pathways are active in the support of DNA replication (Figure 2), including translesion DNA synthesis (TLS; see chapters by Gan et al. and Andersen et al. in this issue), template switching by fork regression, and HR. Blockage of the replicative polymerase on either the leading or lagging strand can be resolved by a polymerase switch to specialized TLS polymerases that are able to insert bases opposite non-Watson-Crick bases and to extend non-standard primer-templates (Figure 2A, step 3b, and Figure 2B, step 2c). On the basis of genetic and biochemical data, it has been proposed that TLS polymerases are highly specialized in these functions, requiring one polymerase for base insertion and another for extension before a switch back to the replicative polymerase ( $\delta$ or $\varepsilon$ presumably) [117]. Fork regression involves a template switch of the blocked $3^{\prime}$ end to the nascent sister strand, involving the formation of a so-called chicken foot intermediate, a structure that is analogous to a Holliday junction (Figure 2A, steps $3 \mathrm{~d}$ and $4 d)$. This template switch does not involve strand invasion and is likely independent of Rad51. RPA and DNA annealing by Rad52 protein might be involved, as well as unknown motor proteins that catalyze the formation and dissolution of the chicken foot. Reversal of the chicken foot after template switch and DNA synthesis leads to tolerance of the blocking damage and direct replication restart (Figure 2A, step 5d) [118].

$\mathrm{HR}$ is required for gap repair and the repair of one-sided DSBs (Figure 2A, steps 3a-4a-5a, 3c-4c-5c and Figure 2B, steps 2a-3a-4, 2b-3b-4). Reinitiation of DNA synthesis after polymerase blockage can occur on the lagging strand, but was recently also shown to occur on the leading strand $[119,120]$. Hence, gaps can occur on both leading and lagging strands. These gaps may also be resolved by TLS polymerases (see chapters by Gan et al. and Andersen et al. in this issue). Template-switching by HR can be envisioned to occur in two ways (Figure 2B, steps $2 \mathrm{a}-3 \mathrm{a}$ or $2 \mathrm{~b}-3 \mathrm{~b}$ ), depending on which strand invades the undamaged template. The outcome of both mechanisms, lesion bypass and damage tolerance (Figure 2B, step 4), is the same, but the intermediates involved and the enzymatic functions differ. First, the uninterrupted strand can serve as a template for Rad51 filament formation and invade the sister chromatid (Figure 2A, steps 3c-4c-5c and Figure 2B, 2a-3a-4). The displaced strand of the D-loop would serve as template for the blocked 3'-OH end. This mechanism involves the formation of a paranemic joint, where the paired strands cannot truly intertwine due of the lack of an end. These joints are known to be unstable [121] and may require specific cofactors for Rad51. Alternatively, a 5'-3'DNA helicase could dislodge the blocked strand, leading to Rad51 filament assembly on the interrupted strand and formation of a D-loop (Figure 2B, steps 2b-3b). It is not known which helicase might participate in this reaction, but the RecQlike helicases are excluded, because they unwind DNA in the opposite, 3'-5' direction [122].

One-sided DSBs may originate from direct endonucleolytic action at stalled forks or indirectly when the fork encounters a nick in the DNA. In the repair of one-sided DSBs, HR appears to be the only pathway leading to their productive resolution (Figure 2A, steps. 2a-3a-4a-5a). Formally analogous to BIR (Figure 1, right), the DSB is resected to form a 3'-tailed end for Rad51 filament assembly and DNA strand invasion. Work in bacteria established that the critical step in replication fork restart (and by implication BIR) is reloading of the replicative helicase [118]. The PriA $3^{\prime}-5^{\prime}$ helicase is critical for loading of the replicative helicase at D-loops, but the mechanisms and proteins involved in this step in eukaryotes are not known. Another mechanistic aspect of one-sided DSB repair by HR is the formation of a single Holliday junction (Figure 2A, steps $4 a-5 a)$, which requires resolution prior to chromosome segregation.

The presumptive mechanisms of replication fork support by HR require additional factors that are not required in DSB repair. As depicted in Figure 2, different sets of junctions are formed and processed. Additionally, Rad51 filaments may form at a gap rather than a tailed DSB. Several genes have been identified in yeast that genetically map into the RAD52 (HR) epistasis group, but the corresponding mutants did not display sensitivity to DSBs, the hallmark phenotype of an HR defect in this organism. Interestingly, such mutants are sensitive to agents that stall replication forks and may represent examples of context-specific HR proteins acting primarily during replication fork support. The budding yeast Shu1-Psy3-Shu2-Csm2 complex falls into this category (Table 1). The members of this complex have been identified as suppressors of the slow growth caused by a mutation in the TOP 3 gene [123]. Genetic analysis suggests that the Shu complex is involved in the formation of recombination intermediates that require processing by Sgs1-Top3-Rmi1 [124]. Members of the Shu complex display functional and structural homology to mammalian Rad51 paralogs (Table 1; Shu1 to Xrcc2, Psy3 to Rad51D) [125]. This suggests that the Shu complex may have a specialized role in Rad51 filament formation 
during replication fork support.

Also the Mus81-Mms4 complex (Table 1) appears to be a replication context-specific cofactor of HR (reviewed in $[126,127])$. Cells deficient for the complex are not sensitive to DSBs induced by $\mathrm{HO}$ endonuclease or IR, but display sensitivity to fork-stalling agents like methylmethane sulfonate (MMS), UV, and the ribonucleotide reductase inhibitor hydroxyurea as well as the topoisomerase I inhibitor camptothecin $[128,129]$. The mus 81 mms 4 mutants are epistatic with the RAD52 group for these phenotypes. Mus81-Mms4 is a structure-selective DNA endonuclease that cleaves a number of substrates in vitro, including replication fork-like substrates, nicked Holliday junctions, D-loops, and 3'-flaps (reviewed in [126, 127]). A number of potential Mus81-Mms4 substrates are envisioned to arise during the processing of stalled replication forks (Figure 2). The in vivo substrate(s) of Mus81-Mms4 remain to be determined. Mus81-Mms4 has also been identified to be involved in ICL repair in mammalian cells (see below).

In sum, a complex web of pathways support stalled or broken replication forks. The data suggest that use of TLS, HR, and template switching by fork regression may entail a regulated hierarchy, likely involving the mono- and poly-ubiquitylation of PCNA [130-132]. HR-independent template switching (chicken foot formation) is actively repressed by DNA damage checkpoints at forks stalled by depleting nucleotides by addition of hydroxyurea [133]. HR is actively counteracted during S-phase through the recruitment of the Srs2 anti-recombinase by K164-sumoylated PCNA [134, 135]. Srs2 DNA helicase exerts its anti-recombinogenic function by dissociating $\operatorname{Rad} 51$ from ssDNA, opposing the formation of the presynaptic filament necessary for DNA strand invasion [104, 136]. In addition, efficient $\mathrm{HR}$ after replication fork stalling requires activating phosphorylation of the Rad55-Rad57 mediator complex by DNA damage checkpoint kinases [137]. These data suggest that TLS is the preferred option at stalled forks, but this choice may be affected by the chromosomal context or by the specific way the fork was stalled or broken. In conclusion, HR in replication fork support requires not only the core program of Rad51 filament formation and DNA strand invasion but also context-specific factors, such as Mus81-Mms4, that may have little or no role in HR during DSB repair.

\section{Homologous recombination and DNA interstrand crosslink repair}

DNA ICLs are one of the most deleterious DNA lesions. By covalently linking the Watson and Crick strands of the double helix, ICLs obstruct DNA replication and transcription (reviews in refs. $[138,139])$. ICL-inducing agents usually generate multiple types of DNA damage besides ICLs, such as DNA mono-adducts, intrastrand crosslinks, and DNA-protein crosslink. Although ICLs comprise only a small fraction of the induced damage, these are the most cytotoxic and genotoxic lesions produced. ICL-inducing agents exist in natural sources like certain medicinal and edible plants, as well as some endogenously produced metabolites. Malondialdehyde, a metabolite of lipid peroxidation and prostaglandin biosynthesis, preferentially crosslinks two deoxyguanosine residues on the opposite strands of the sequence $d(\mathrm{CpG})$. Studies in human cells show that malondialdehyde is highly mutagenic, suggesting that malondialdehyde may be an endogenous source of ICLs [140]. Due to their high toxicity and selectivity against proliferating cells, a variety of ICL-inducing agents, including psoralens, cis-platinum, and mitomycin $\mathrm{C}$, are widely utilized in cancer chemotherapy $[138,139,141]$. Sensitivity to ICL agents is a hallmark of mammalian HR defects and of cells derived from FA patients $[12,13]$ (see below).

NER, HR, and TLS pathways participate in ICL repair in eukaryotes $[138,139]$. Recognition of ICL lesions likely involves the formation of stalled replication forks (Figure 3 , step 2), yet the detailed mechanism is unknown. In eukaryotes, DSBs near the ICL site have been observed as a pivotal intermediate of ICL repair [142, 143]. Ensuing repair of the one-sided DSB by HR may involve lesion processing by NER (Figure 3 left, steps $4 \mathrm{a}$ and 8 ) and TLS polymerases (steps $5 \mathrm{a}$ and $7 \mathrm{a}$ ). A more complex scheme (Figure 3 right, steps 4b-7b) involves D-loop formation and DNA synthesis on the undamaged homolog prior to DNA strand invasion on the sister chromatid downstream of the blocking lesion, leading to damage tolerance.

In mammalian cells, the hMus81-Eme1 structure-selective endonuclease was recently identified to be required for DSB formation after mitomycin $\mathrm{C}$ and cis-platinum treatment [144]. Replication fork-like structures are an excellent substrate for the enzyme in vitro (reviewed in $[126,127]$ ) (Figure 3, step 2). Unhooking of the lesion for repair (Figure 3, steps 4a and 8) has been proposed to be accomplished by the XPF-Ercc1 endonuclease, a key factor in NER [145]. Mus81-Mms4/Eme1 and XPF-Ercc1 are related endonucleases, but neither appears to be required for DSB formation during ICL repair in yeast (see ref. [139]). A third nuclease with a specific function in ICL repair is Pso2/Smn1. The protein exhibits a 5'-3' DNA exonuclease activity, which is required after DSB formation [146-148]. Unlike mammalian Mus81 or XPF-deficient cells that are sensitive to several ICL-inducing agents [144, 145], mouse smn $1^{-/}$cells were sensitive only to mitomycin $\mathrm{C}$ but not other ICL agents [149]. In yeast, however, pso2/smn 1 mutants display sensitivity to a spectrum of ICL agents [139]. The 
difference between these organisms is further accentuated by the existence of the FA pathway that is critical for ICL repair in humans but absent in yeast (an exception being the FANCM homolog Mph1) [12, 13].

FA is a rare, recessive chromosomal-instability disorder, and cells from FA patients display a diagnostic sensitivity to DNA crosslinking agents. The genes for 13 known FA complementation groups (called $F A N C$ genes) groups have now been identified [12, 13, 150-152]. A nuclear E3 mono-ubiquitin ligase core complex consisting of FANCA, B, C, E, F, G, L, M, and FAAP24 ubiquitylates the FANCD2-FANCI complex upon encountering stalled replication forks. This modification leads to colocalization of FANCD2-FANCI with HR proteins in DNA damage-induced foci together with BRCA2 (corresponding to FANCD1) possibly in conjunction with its interacting partner FANCN (PALB2). FANCJ has previously been identified as the DNA helicase BACH1/BRIP and also functions downstream of FANCD2 ubiquitylation. The molecular impact of FANCD2 ubiquitylation on BRCA2FANCN or FANCJ function is not known. Here, we focus the discussion on FANCM-FAAP24, FANCJ and FANCD1 (BRCA2), because these proteins interact directly with DNA. FANCN co-localizes with BRCA2 in foci and is required for BRCA2 focus formation, but its mechanistic role is unknown [54].

FANCM and FAAP24 are required for activation of the core complex to ubiquitylate FANCD2-FANCI. Although FANCM is a member of the DNA helicase superfamily 2 , it is unable to catalyze strand separation and is rather a dsDNA translocase [153]. Studies in chicken DT40 cells showed that the motor domain is critical for its biological function $[153,154]$. FANCM-FAAP24 form an XPF family heterodimer that lacks nuclease activity but has dsDNA translocase activity, as inferred from the activity of FANCM in the absence of FAAP24 [153, 155]. FANCM is proposed to be a sensor for stalled forks, and this specificity could be provided by FAAP24 that preferentially binds to splayed DNA [153, 155]. Based on the ability of other superfamily 2 dsDNA translocases to remodel protein-dsDNA complexes [156] (e.g. Rad54 [67]; see above), it could be speculated that FANCM-FAAP24 remodels stalled forks to allow their processing. FANCJ (=BACH1/BRIP1) is a DNA helicase, capable of strand separation with a $5^{\prime}-3^{\prime}$ polarity [157]. Together with BRCA2, in conjunction with the BRCA2binding partner FANCN, they are the only FANC proteins to function downstream of FANCD2, suggesting that these proteins might function in concert. The role of BRCA2 in Rad51 filament formation has been discussed above (see also [6]). The physical interaction of FANCJ with RPA [158] is consistent with a possible role in an early step in HR leading to the formation of the presynaptic Rad51 filament on ssDNA. Despite the remarkable progress in identifying the FANC genes, the mechanistic role of the FANC core ubiquitylation complex and how FANCD2-FANCI ubiquitylation impacts ICL repair remain unknown.

In conclusion, ICL repair is very complex, involving proteins from the NER, HR and TLS pathways. Substantial mechanistic differences appear to exist between yeast and mammalian ICL repair, although the pathways are incompletely understood at present. In addition, mammals contain a new suite of genes, the FA pathway, which appear to be critical for the recruitment of Rad51-mediated HR during ICL repair.

\section{Conclusion}

At the nexus of DNA repair and DNA replication, HR constitutes a key pathway to maintain genomic stability. HR supports DNA replication and aids replication restart after fork stalling or breakage. DNA replication in turn affords the ideal damage recognition process, checking the entire genome, base by base, for lesions that interfere not only with replication, but also with other DNA functions such as transcription. The human tumor suppressor protein BRCA2 highlights the connection between HR and cancer predisposition, and it is likely that mutations in other HR proteins will be shown to influence cancer risk. BRCA2 also epitomizes the intersection between HR and FA, but the mechanisms involved in ICL repair and the specific contributions of BRCA2 and the other FANC genes to this process remain to be elucidated. In the past, DNA repair pathways have been neatly separated on the basis of genetic and biochemical criteria. Now it has become apparent that many DNA metabolic processes are intertwined. One of the consequences of this functional integration between DNA replication and the various DNA damage repair/tolerance pathways is the added complexity brought about by regulatory decisions governing how a specific lesion is processed. Hence, besides the need to elucidate the process of HR in repair and replication fork support, more attention will focus on these regulatory mechanisms in the future.

\section{Acknowledgments}

The support of our research by the National Institutes of Health, the Susan G Komen Breast Cancer Foundation, and University of California BioStar program (USA) is gratefully acknowledged. We thank all members of the Heyer lab for discussion and critical comments on the manuscript. We offer our sincere apologies for omitting all the references and great work that could not be discussed here due to space limitations. 


\section{References}

1 Friedberg EC, Walker GC, Siede W, et al. DNA Repair and Mutagenesis. 2nd Edition. Washington, DC: ASM Press, 2006.

2 Hunter N. Meiotic recombination. In: Aguilera A, Rothstein R. eds. Homologous recombination. Berlin-Heidelberg: SpringerVerlag, 2007:381-441.

3 Heyer WD. Biochemistry of eukaryotic homologous recombination. In: Aguilera A, Rothstein R, eds. Molecular genetics of recombination. Berlin-Heidelberg: Springer-Verlag, 2007:95133.

4 Paques F, Haber JE. Multiple pathways of recombination induced by double-strand breaks in Saccharomyces cerevisiae. Microbiol Mol Biol Rev 1999; 63:349-404.

5 Sung P, Klein H. Mechanism of homologous recombination: mediators and helicases take on regulatory functions. Nat Rev Mol Cell Biol 2006; 7:739-750.

6 West SC. Molecular views of recombination proteins and their control. Nat Rev Mol Cell Biol 2003; 4:435-445.

7 Wyman C, Kanaar R. DNA double-strand break repair: All's well that ends well. Annu Rev Genet 2006; 40:363-383.

8 Kuzminov A. Recombinational repair of DNA damage in Escherichia coli and bacteriophage lambda. Microbiol Mol Biol Rev 1999; 63:751-813.

9 Krogh BO, Symington LS. Recombination proteins in yeast. Annu Rev Genet 2004; 38:233-271.

10 Christ N, Moynahan ME, Jasin M. BRCA2: safeguarding the genome through homologous recombination. In: Aguilera A, Rothstein R. eds. Molecular genetics of recombination. BerlinHeidelberg: Springer-Verlag, 2007:363-380.

11 Pellegrini L, Venkitaraman A. Emerging functions of BRCA2 in DNA recombination. Trends Biochem Sci 2004; 29:310-316.

12 Kennedy RD, D'Andrea AD. The Fanconi Anemia/BRCA pathway: new faces in the crowd. Genes Dev 2005; 19:2925-2940.

13 Patel KJ, Joenje H. Fanconi anemia and DNA replication repair. DNA Repair (Amst) 2007; 6:885-890.

14 Wold MS. Replication protein A: heterotrimeric, single-stranded DNA-binding protein required for eukaryotic DNA metabolism. Annu Rev Biochem 1997; 66:61-92.

15 Sung P. Catalysis of ATP-dependent homologous DNA pairing and strand exchange by yeast RAD51 protein. Science 1994; 265:1241-1243.

16 Conway AB, Lynch TW, Zhang Y, et al. Crystal structure of a Rad51 filament. Nat Struct Mol Biol 2004; 11:791-796.

17 Ogawa T, Yu X, Shinohara A, Egelman EH. Similarity of the yeast RAD51 filament to the bacterial RecA filament. Science 1993; 259:1896-1899.

18 Bianco PR, Tracy RB, Kowalczykowski SC. DNA strand exchange proteins: a biochemical and physical comparison. Front Biosci 1998; 3:570-603.

19 Zaitseva EM, Zaitsev EN, Kowalczykowski SC. The DNA binding properties of Saccharomyces cerevisiae $\operatorname{Rad} 51$ protein. J Biol Chem 1999; 274:2907-2915.

20 Eggler AL, Inman RB, Cox MM. The Rad51-dependent pairing of long DNA substrates is stabilized by replication protein A. $J$ Biol Chem 2002; 277:39280-39288.

21 Sugiyama T, Zaitseva EM, Kowalczykowski SC. A singlestranded DNA-binding protein is needed for efficient presynaptic complex formation by the Saccharomyces cerevisiae Rad51 protein. J Biol Chem 1997; 272:7940-7945.

22 Beernink HTH, Morrical SW. RMPs: recombination/replication mediator proteins. Trends Biochem Sci 1999; 24:385-389.

23 Lisby M, Barlow JH, Burgess RC, Rothstein R. Choreography of the DNA damage response: spatiotemporal relationships among checkpoint and repair proteins. Cell 2004; 118:699-713.

24 Gasior SL, Wong AK, Kora Y, Shinohara A, Bishop DK. Rad52 associates with RPA and functions with Rad55 and Rad57 to assemble meiotic recombination complexes. Genes Dev 1998; 12:2208-2221.

25 Sugawara N, Wang X, Haber JE. In vivo roles of Rad52, Rad54, and Rad55 proteins in Rad51-mediated recombination. Mol Cell 2003; 12:209-219.

26 Sung P. Yeast Rad55 and Rad57 proteins form a heterodimer that functions with replication protein A to promote DNA strand exchange by Rad51 recombinase. Genes Dev 1997; 11:11111121.

27 Thacker J. A surfeit of RAD51-like genes? Trends Genet 1999; 15:166-168.

28 Masson JY, Tarsounas MC, Stasiak AZ, et al. Identification and purification of two distinct complexes containing the five RAD51 paralogs. Genes Dev 2001; 15:3296-3307.

29 Schild D, Lio YC, Collins DW, Tsomondo T, Chen DJ. Evidence for simultaneous protein interactions between human Rad51 paralogs. J Biol Chem 2000; 275:16443-16449.

30 Sigurdsson S, Van Komen S, Bussen W, et al. Mediator function of the human Rad51B-Rad51C complex in Rad51/RPA-catalyzed DNA strand exchange. Genes Dev 2001; 15:3308-3318.

31 Yonetani Y, Hochegger H, Sonoda E, et al. Differential and collaborative actions of Rad51 paralog proteins in cellular response to DNA damage. Nucleic Acids Res 2005; 33:4544-4552.

32 Shinohara A, Shinohara M, Ohta T, Matsuda S, Ogawa T. Rad52 forms ring structures and co-operates with RPA in single-strand annealing. Genes Cells 1998; 3:145-156.

33 Singleton MR, Wentzell LM, Liu YL, West SC, Wigley DB. Structure of the single-strand annealing domain of human RAD52 protein. Proc Natl Acad Sci USA 2002; 99:13492-13497.

34 Shinohara A, Ogawa H, Ogawa T. Rad51 protein involved in repair and recombination in $S$. cerevisiae is a RecA-like protein. Cell 1992; 69:457-470.

35 Hays SL, Firmenich AA, Massey P, Banerjee R, Berg P. Studies of the interaction between Rad52 protein and the yeast single-stranded DNA binding protein RPA. Mol Cell Biol 1998; 18:4400-4406.

36 Sugiyama T, Kowalczykowski SC. Rad52 protein associates with replication protein A (RPA)-single-stranded DNA to accelerate Rad51-mediated displacement of RPA and presynaptic complex formation. J Biol Chem 2002; 277:31663-31672.

37 New JH, Sugiyama T, Zaitseva E, Kowalczykowski SC. Rad52 protein stimulates DNA strand exchange by Rad51 and replication protein A. Nature 1998; 391:407-410.

38 Shinohara A, Ogawa T. Stimulation by Rad52 of yeast Rad51mediated recombination. Nature 1998; 391:404-407.

39 Sung P. Function of yeast Rad52 protein as a mediator between replication protein A and the Rad51 recombinase. J Biol Chem 1997; 272:28194-28197.

40 Sugiyama T, New JH, Kowalczykowski SC. DNA annealing by $\operatorname{Rad} 52$ Protein is stimulated by specific interaction with the complex of replication protein A and single-stranded DNA. Proc 
Natl Acad Sci USA 1998; 95:6049-6054.

41 Sugiyama T, Kantake N, Wu Y, Kowalczykowski SC. Rad52mediated DNA annealing after Rad51-mediated DNA strand exchange promotes second ssDNA capture. EMBO J 2006; 25:5539-5548.

42 Rijkers T, VandenOuweland J, Morolli B, et al. Targeted inactivation of mouse RAD52 reduces homologous recombination but not resistance to ionizing radiation. Mol Cell Biol 1998; 18:6423-6429.

43 Fujimori A, Tachiiri S, Sonoda E, et al. Rad52 partially substitutes for the Rad51 paralog XRCC3 in maintaining chromosomal integrity in vertebrate cells. EMBO J 2001; 20:5513-5520.

44 Tarsounas M, Davies D, West SC. BRCA2-dependent and independent formation of RAD51 nuclear foci. Oncogene 2003; 22:1115-1123.

45 Yang HJ, Li QB, Fan J, Holloman WK, Pavletich NP. The BRCA2 homologue Brh2 nucleates RAD51 filament formation at a dsDNA-ssDNA junction. Nature 2005; 433:653-657.

46 San Filippo J, Chi P, Sehorn MG, et al. Recombination mediator and Rad51 targeting activities of a human BRCA2 polypeptide. J Biol Chem 2006; 281:11649-11657.

47 Yang HJ, Jeffrey PD, Miller J, et al. BRCA2 function in DNA binding and recombination from a BRCA2-DSS1-ssDNA structure. Science 2002; 297:1837-1848.

48 Pellegrini L, Yu DS, Lo T, et al. Insights into DNA recombination from the structure of a RAD51-BRCA2 complex. Nature 2002; 420:287-293.

49 Davies OR, Pellegrini L. Interaction with the BRCA2 C terminus protects RAD51-DNA filaments from disassembly by BRC repeats. Nat Struct Mol Biol 2007; 14:475-483.

50 Esashi F, Galkin VE, Yu X, Egelman EH, West SC. Stabilization of RAD51 nucleoprotein filaments by the C-terminal region of BRCA2. Nat Struct Mol Biol 2007; 14:468-474.

51 Esashi F, Christ N, Gannon J, et al. CDK-dependent phosphorylation of BRCA2 as a regulatory mechanism for recombinational repair. Nature 2005; 434:598-604.

52 Gudmundsdottir K, Lord CJ, Witt E, Tutt ANJ, Ashworth A. DSS1 is required for RAD51 focus formation and genomic stability in mammalian cells. EMBO Rep 2004; 5:989-993.

53 Kojic M, Yang HJ, Kostrub CF, Pavletich NP, Holloman WK. The BRCA2-interacting protein DSS1 is vital for DNA repair, recombination, and genome stability in Ustilago maydis. Mol Cell 2003; 12:1043-1049.

54 Xia B, Sheng Q, Nakanishi K, et al. Control of BRCA2 cellular and clinical functions by a nuclear partner, PALB2. Mol Cell 2006; 22:719-729.

55 Lu HM, Guo X, Meng XB, et al. The BRCA2-interacting protein BCCIP functions in RAD51 and BRCA2 focus formation and homologous recombinational repair. Mol Biol Cell 2005; 25:1949-1957.

56 Heyer WD, Li X, Rolfsmeier M, Zhang XP. Rad54: the Swiss Army knife of homologous recombination? Nucl Acids Res 2006; 34:4115-4125.

57 Tan TLR, Kanaar R, Wyman C. Rad54, a Jack of all trades in homologous recombination. DNA Repair 2003; 2:787-794.

58 Sharan SK, Morimatsu M, Albrecht U, et al. Embryonic lethality and radiation hypersensitivity mediated by Rad51 in mice lacking Brca2. Nature 1997; 386:804-810.

59 Essers J, Hendriks RW, Swagemakers SMA, et al. Disruption of mouse $R A D 54$ reduces ionizing radiation resistance. Cell 1997; 89:195-204.

60 Wesoly J, Agarwal S, Sigurdsson S, et al. Differential contributions of mammalian Rad54 paralogs to recombination, DNA damage repair, and meiosis. Mol Cell Biol 2006; 26:976-989.

61 Amitani I, Baskin RJ, Kowalczykowski SC. Visualization of Rad54, a chromatin remodeling protein, translocating on single DNA molecules. Mol Cell 2006; 23:143-148.

62 Mazin AV, Alexeev AA, Kowalczykowski SC. A novel function of Rad54 protein - Stabilization of the Rad51 nucleoprotein filament. J Biol Chem 2003; 278:14029-14036.

63 Wolner B, Peterson CL. ATP-dependent and ATP-independent roles for the Rad54 chromatin remodeling enzyme during recombinational repair of a DNA double strand break. J Biol Chem 2005; 280:10855-10860.

64 Mazin AV, Bornarth CJ, Solinger JA, Heyer W-D, Kowalczykowski SC. Rad54 protein is targeted to pairing loci by the Rad51 nucleoprotein filament. Mol Cell 2000; 6:583-592.

65 Van Komen S, Petukhova G, Sigurdsson S, Stratton S, Sung P. Superhelicity-driven homologous DNA pairing by yeast recombination factors Rad51 and Rad54. Mol Cell 2000; 6:563-572.

66 Petukhova G, Stratton S, Sung P. Catalysis of homologous DNA pairing by yeast Rad51 and Rad54 proteins. Nature 1998; 393:9194.

67 Solinger JA, Kiianitsa K, Heyer W-D. Rad54, a Swi2/Snf2-like recombinational repair protein, disassembles Rad51:dsDNA filaments. Mol Cell 2002; 10:1175-1188.

$68 \mathrm{Li} \mathrm{X}$, Heyer WD. Rad54 controls access to the invading 3' end in Rad51-mediated strand invasion during homologous recombination in S. cerevisiae. 2007; in submission.

69 Alexeev A, Mazin A, Kowalczykowski SC. Rad54 protein possesses chromatin-remodeling activity stimulated by a Rad51ssDNA nucleoprotein filament. Nat Struct Biol 2003; 10:182186.

70 Jaskelioff M, Van Komen S, Krebs JE, Sung P, Peterson CL. $\operatorname{Rad} 54 \mathrm{p}$ is a chromatin remodeling enzyme required for heteroduplex joint formation with chromatin. J Biol Chem 2003; 278:9212-9218.

71 Zhang Z, Fan HY, Goldman JA, Kingston RE. Homology-driven chromatin remodeling by human RAD54. Nat Struct Mol Biol 2007; 14:397-405.

72 Bugreev DV, Hanaoka F, Mazin AV. Rad54 dissociates homologous recombination intermediates by branch migration. Nat Struct Mol Biol 2007; 14:746-753.

73 Bugreev DV, Mazina OM, Mazin AV. Rad54 protein promotes branch migration of Holliday junctions. Nature 2006; 442:590593.

74 Miyazaki T, Bressan DA, Shinohara M, Haber JE, Shinohara A. In vivo assembly and disassembly of Rad51 and Rad52 complexes during double-strand break repair. EMBO J 2004; 23:939-949.

75 Takata M, Sasaki MS, Sonoda E, et al. The Rad51 paralog Rad51B promotes homologous recombinational repair. Mol Cell Biol 2000; 20:6476-6482.

76 Hoeijmakers JHJ. Genome maintenance mechanisms for preventing cancer. Nature 2001; 411:366-374.

77 McClintock B. The stability of broken ends of chromosomes in Zea Mays. Genetics 1941; 26:234-282.

78 Engels WR, Johnson-Schlitz DM, Eggleston WB, Sved J. Highfrequency P element loss in Drosophila is homolog dependent. 
Cell 1990; 62:515-525.

79 Dudley DD, Chaudhuri J, Bassing CH, Alt FW. Mechanism and control of V(D)J recombination versus class switch recombination: similarities and differences. Adv Immunolo 2005; 86:43112.

80 Ward JF. DNA damage produced by ionizing radiation in mammalian cells: identities, mechanisms of formation, and reparability. Prog Nucleic Acid Res Mol Biol 1988; 35:95-125.

81 Povirk LF. DNA damage and mutagenesis by radiomimetic DNA-cleaving agents: bleomycin, neocarzinostatin and other enediynes. Mutat Res 1996; 355:71-89.

82 Li TK, Liu LF. Tumor cell death induced by topoisomerasetargeting drugs. Annu Rev Pharmacol Toxicol 2001; 41:53-77.

83 Wang JC. Cellular roles of DNA topoisomerases: a molecular perspective. Nat Rev Mol Cell Biol 2002; 3:430-440.

84 Koster DA, Palle K, Bot ES, Bjornsti MA, Dekker NH. Antitumour drugs impede DNA uncoiling by topoisomerase I. Nature 2007; 448:213-217.

85 Pouliot JJ, Yao KC, Robertson CA, Nash HA. Yeast gene for a Tyr-DNA phosphodiesterase that repairs topoisomerase I complexes. Science 1999; 286:552-555.

86 Interthal H, Pouliot JJ, Champoux JJ. The tyrosyl-DNA phosphodiesterase Tdp1 is a member of the phospholipase D superfamily. Proc Natl Acad Sci USA 2001; 98:12009-12014.

87 Pierce AJ, Hu P, Han M, Ellis N, Jasin M. Ku DNA end-binding protein modulates homologous repair of double-strand breaks in mammalian cells. Genes Dev 2001; 15:3237-3242.

88 Szostak JW, Orr-Weaver TL, Rothstein RJ, Stahl FW. The double-strand-break repair model for recombination. Cell 1983; 33:25-35.

89 Nassif N, Penney J, Pal S, Engels WR, Gloor GB. Efficient copying of nonhomolgous sequences from ectopic sites via P-element-induced gap repair. Mol Cell Biol 1994; 14:1613-1625.

90 Malkova A, Ivanov EL, Haber JE. Double-strand break repair in the absence of RAD51 in yeast: a possible role for break-induced DNA replication. Proc Natl Acad Sci USA 1996; 93:71317136.

91 Mosig G. Recombination and recombination-dependent DNA replication in bacteriophage T4. Annu Rev Genet 1998; 32:379413, C371.

92 Ivanov EL, Sugawara N, White CI, Fabre F, Haber JE. Mutations in Xrs2 and Rad50 delay but do not prevent mating-type switching in Saccharomyces cerevisiae. Mol Cell Biol 1994; 14:3414-3425.

93 Krishna S, Wagener BM, Liu HP, et al. Mre11 and Ku regulation of double-strand break repair by gene conversion and breakinduced replication. DNA Repair (Amst) 2007; 6:797-808.

94 Fiorentini P, Huang KN, Tishkoff DX, Kolodner RD, Symington LS. Exonuclease I of Saccharomyces cerevisiae functions in mitotic recombination in vivo and in vitro. Mol Cell Biol 1997; 17:2764-2773.

95 Clerici M, Mantiero D, Lucchini G, Longhese MP. The Saccharomyces cerevisiae $\mathrm{Sae} 2$ protein promotes resection and bridging of double strand break ends. J Biol Chem 2005; 280:3863138638.

96 Liu YL, Masson JY, Shah R, O'Regan P, West SC. RAD51C is required for Holliday junction processing in mammalian cells. Science 2004; 303:243-246.

$97 \mathrm{Wu}$ LJ, Hickson ID. The Bloom's syndrome helicase suppresses crossing-over during homologous recombination. Nature 2003; 426:870-874.

98 Plank JL, Wu JH, Hsieh TS. Topoisomerase III alpha and Bloom's helicase can resolve a mobile double Holliday junction substrate through convergent branch migration. Proc Natl Acad Sci USA 2006; 103:11118-11123.

$99 \mathrm{Wu}$ L, Bachrati CZ, Ou JW, et al. BLAP75/RMI1 promotes the BLM-dependent dissolution of homologous recombination intermediates. Proc Natl Acad Sci USA 2006; 103:4068-4073.

100 Lo YC, Paffett KS, Amit O, et al. Sgs 1 regulates gene conversion tract lengths and crossovers independently of its helicase activity. Mol Cell Biol 2006; 26:4086-4094.

101 Oh SD, Lao JP, Hwang PYH, et al. BLM ortholog, Sgs1, prevents aberrant crossing-over by suppressing formation of multichromatid joint molecules. Cell 2007; 130:259-272.

102 Petalcorin MIR, Sandall J, Wigiley DB, Boulton SJ. CeBRC-2 stimulates D-loop formation by RAD-51 and promotes DNA single-strand annealing. J Mol Biol 2006; 361:231-242.

103 Ira G, Malkova A, Liberi G, Foiani M, Haber JE. Srs2 and Sgs1Top3 suppress crossovers during double-strand break repair in yeast. Cell 2003; 115:401-411.

104 Veaute X, Jeusset J, Soustelle C, et al. The Srs2 helicase prevents recombination by disrupting Rad51 nucleoprotein filaments. Nature 2003; 423:309-312.

105 Adams MD, McVey M, Sekelsky JJ. Drosophila BLM in doublestrand break repair by synthesis-dependent strand annealing. Science 2003; 299:265-267.

106Bachrati CZ, Borts RH, Hickson ID. Mobile D-loops are a preferred substrate for the Bloom's syndrome helicase. Nucleic Acids Res 2006; 34:2269-2279.

107Elliott B, Jasin M. Double-strand breaks and translocations in cancer. Cell Mol Life Sci 2002; 59:373-385.

108Richardson C, Jasin M. Frequent chromosomal translocations induced by DNA double-strand breaks. Nature 2000; 405:697700.

109Moynahan ME, Jasin M. Loss of heterozygosity induced by a chromosomal double-strand break. Proc Natl Acad Sci USA 1997; 94:8988-8993.

110 Lydeard JR, Jain S, Yamaguchi M, Haber JE. Break-induced replication and telomerase-independent telomere maintenance require Pol32. Nature 2007; 448:820-823.

111 Nickoloff JA, Sweetser DB, Clikeman JA, Khalsa GJ, Wheeler SL. Multiple heterologies increase mitotic double-strand breakinduced allelic gene conversion tract lengths in yeast. Genetics 1999; 153:665-679.

112 Dunham MA, Neumann AA, Fasching CL, Reddel RR. Telomere maintenance by recombination in human cells. Nat Genet 2000; 26:447-450.

113 Ira G, Pellicioli A, Balijja A, et al. DNA end resection, homologous recombination and DNA damage checkpoint activation require CDK1. Nature 2004; 431:1011-1017.

114 Freudenreich CH. Chromosome fragility: molecular mechanisms and cellular consequences. Front Biosci 2007; 12:4911-4924.

115 Azvolinsky A, Dunaway S, Torres JZ, Bessler JB, Zakian VA. The $S$-cerevisiae Rrm3p DNA helicase moves with the replication fork and affects replication of all yeast chromosomes. Genes Dev 2006; 20:3104-3116.

116 Kolodner RD, Putnam CD, Myung K. Maintenance of genome stability in Saccharomyces cerevisiae. Science 2002; 297:552- 
557.

117 Prakash S, Prakash L. Translesion DNA synthesis in eukaryotes: a one- or two-polymerase affair. Genes Dev 2002; 16:18721883.

118 Heller RC, Marians KJ. Replisome assembly and the direct restart of stalled replication forks. Nat Rev Mol Cell Biol 2006; 7:932-943.

119 Heller RC, Marians KJ. Replication fork reactivation downstream of a blocked nascent leading strand. Nature 2006; 439:557562.

120Lopes M, Foiani M, Sogo JM. Multiple mechanisms control chromosome integrity after replication fork uncoupling and restart at irreparable UV lesions. Mol Cell 2006; 21:15-27.

121Bianchi M, DasGupta C, Radding CM. Synapsis and the formation of paranemic joints by E. coli RecA protein. Cell 1983; 34:931-939.

122Hickson ID. RecQ helicases: caretakers of the genome. Nat Rev Cancer 2003; 3:169-178.

123 Shor E, Weinstein J, Rothstein R. Genetic screen for top3 suppressors in Saccharomyces cerevisiae identifies SHU1, SHU2, PSY3 and CSM2: four genes involved in error-free DNA repair. Genetics 2005; 169:1275-1289.

124Mankouri HW, Ngo HP, Hickson ID. Shu proteins promote the formation of homologous recombination intermediates that are processed by sgs1-rmi1-top3. Mol Biol Cell 2007; 18:40624073.

125 Martin V, Chahwan C, Gao H, et al. Sws1 is a conserved regulator of homologous recombination in eukaryotic cells. EMBO J 2006; 25:2564-2574.

126Hollingsworth NM, Brill SJ. The Mus81 solution to resolution: generating meiotic crossovers without Holliday junctions. Genes Dev 2004; 18:117-125.

127 Heyer WD, Ehmsen KT, Solinger JA. Holliday junctions in the eukaryotic nucleus: resolution in sight? Trends in Biochem Sci 2003; 10:548-557.

128Boddy MN, Lopez-Girona A, Shanahan P, et al. Damage tolerance protein Mus81 associates with the FHA1 domain of checkpoint kinase Cds1. Mol Cell Biol 2000; 20:8758-8766.

129Interthal H, Heyer WD. MUS81 encodes a novel helix-hairpinhelix protein involved in the response to UV- and methylationinduced DNA damage in Saccharomyces cerevisiae. Mol Gen Genet 2000; 263:812-827.

130 Wood A, Garg P, Burgers PMJ. A ubiquitin-binding motif in the translesion DNA polymerase Rev1 mediates its essential functional interaction with ubiquitinated proliferating cell nuclear antigen in response to DNA damage. J Biol Chem 2007; 282:20256-20263.

131 Stelter P, Ulrich HD. Control of spontaneous and damage-induced mutagenesis by SUMO and ubiquitin conjugation. Nature 2003; 425:188-191.

132Hoege C, Pfander B, Moldovan GL, Pyrowolakis G, Jentsch S. RAD6-dependent DNA repair is linked to modification of PCNA by ubiquitin and SUMO. Nature 2002; 419:135-141.

133 Sogo JM, Lopes M, Foiani M. Fork reversal and ssDNA accumulation at stalled replication forks owing to checkpoint defects. Science 2002; 297:599-602.

134Papouli E, Chen SH, Davies AA, et al. Crosstalk between SUMO and ubiquitin on PCNA is mediated by recruitment of the helicase Srs2p. Mol Cell 2005; 19:123-133.
135Pfander B, Moldovan GL, Sacher M, Hoege C, Jentsch S. SUMOmodified PCNA recruits Srs 2 to prevent recombination during S phase. Nature 2005; 436:428-433.

136Krejci L, Van Komen S, Li Y, et al. DNA helicase Srs2 disrupts the Rad51 presynaptic filament. Nature 2003; 423:305-309.

137Herzberg K, Bashkirov VI, Rolfsmeier M, et al. Phosphorylation of Rad55 on serines 2, 8, and 14 is required for efficient homologous recombination in the recovery of stalled replication forks. Mol Cell Biol 2006; 26:8396-8409.

138Dronkert ML, Kanaar R. Repair of DNA interstrand cross-links. Mutat Res 2001; 486:217-247.

139Lehoczky P, McHugh PJ, Chovanec M. DNA interstrand crosslink repair in Saccharomyces cerevisiae. FEMS Microbiol Rev 2007; 31:109-133.

140 Niedernhofer LJ, Daniels JS, Rouzer CA, Greene RE, Marnett LJ. Malondialdehyde, a product of lipid peroxidation, is mutagenic in human cells. J Biol Chem 2003; 278:31426-31433.

141 McHugh PJ, Spanswick VJ, Hartley JA. Repair of DNA interstrand crosslinks: molecular mechanisms and clinical relevance. Lancet Onc 2001; 2:483-490.

142De Silva IU, McHugh PJ, Clingen PH, Hartley JA. Defining the roles of nucleotide excision repair and recombination in the repair of DNA interstrand cross-links in mammalian cells. Mol Cell Biol 2000; 20:7980-7990.

143 Akkari YM, Bateman RL, Reifsteck CA, Olson SB, Grompe M. DNA replication is required to elicit cellular responses to psoralen-induced DNA interstrand cross-links. Mol Cell Biol 2000; 20:8283-8289.

144Hanada K, Budzowska M, Modesti M, et al. The structurespecific endonuclease Mus81-Eme1 promotes conversion of interstrand DNA crosslinks into double-strands breaks. EMBO J 2006; 25:4921-4932.

145 Niedernhofer LJ, Odijk H, Budzowska M, et al. The structurespecific endonuclease Ercc1-Xpf is required to resolve DNA interstrand cross-link-induced double-strand breaks. Mol Biol Cell 2004; 24:5776-5787.

146Li XR, Hejna J, Moses RE. The yeast Snm1 protein is a DNA 5'-exonuclease. DNA Repair (Amst) 2005; 4:163-170.

147 Li X, Moses RE. The beta-lactamase motif in Snm1 is required for repair of DNA double-strand breaks caused by interstrand crosslinks in S. cerevisiae. DNA Repair (Amst) 2003; 2:121129.

148Hejna J, Philip S, Ott J, Faulkner C, Moses R. The hSNM1 protein is a DNA 5'-exonuclease. Nucl Acids Res 2007; 35:6115-6123.

149Dronkert MLG, de Wit J, Boeve M, et al. Disruption of mouse SNM1 causes increased sensitivity to the DNA interstrand cross-linking agent mitomycin C. Mol Cell Biol 2000; 20:45534561 .

150Smogorzewska A, Matsuoka S, Vinciguerra P, et al. Identification of the FANCI protein, a monoubiquitinated FANCD2 paralog required for DNA repair. Cell 2007; 129:289-301.

151 Reid S, Schindler D, Hanenberg H, et al. Biallelic mutations in PALB2 cause Fanconi anemia subtype FA-N and predispose to childhood cancer. Nat Gen 2007; 39:162-164.

152 Xia B, Dorsman JC, Ameziane N, et al. Fanconi anemia is associated with a defect in the BRCA2 partner PALB2. Nat Gen 2007; 39:159-161.

153 Meetei AR, Medhurst AL, Ling C, et al. A human ortholog of archaeal DNA repair protein Hef is defective in Fanconi anemia 
complementation group M. Nat Gen 2005; 37:958-963.

154Mosedale G, Niedzwiedz W, Alpi A, et al. The vertebrate Hef ortholog is a component of the Fanconi anemia tumor-suppressor pathway. Nat Struct Mol Biol 2005; 12:763-771.

155Ciccia A, Ling C, Coulthard R, et al. Identification of FAAP24, a Fanconi anemia core complex protein that interacts with FANCM. Mol Cell 2007; 25:331-343.

156Pazin MJ, Kadonaga JT. SWI2/SNF2 and related proteins: ATPdriven motors that disrupt protein-DNA interactions? Cell 1997; 88:737-740.
157 Gupta R, Sharma S, Sommers JA, et al. Analysis of the DNA substrate specificity of the human BACH1 helicase associated with breast cancer. J Biol Chem 2005; 280:25450-25460.

158 Gupta R, Sharma S, Sommers JA, et al. FANCJ (BACH1) helicase forms DNA damage inducible foci with replication protein A and interacts physically and functionally with the single-stranded DNA-binding protein. Blood 2007; 110:2390-2398.

159Osman F, Dixon J, Barr AR, Whitby MC. The F-box DNA helicase Fbh1 prevents Rhp51-dependent recombination without mediator proteins. Mol Cell Biol 2005; 25:8084-8096. 